Shobha Malviya MD, Frederick A. Burrows MD FRCPC, Albert E. Johnston MD FRCPC, Lee N. Benson MD FRCPC

\title{
Occasional Survey
}

\section{Anaesthetic experience with paediatric inter- ventional cardiology}

\begin{abstract}
Anaesthetic and sedation techniques, complications and outcomes were reviewed in 176 children undergoing 184 interventional cardiologic procedures. Techniques included sedation only, and ketamine, inhalational or narcotic anaesthesia. Ketamine infusion was the technique most frequently used. Ketamine was associated with a higher incidence of respiratory complications $(P<0.05)$ than the other techniques. The higher incidence of hypercarbia (15.6 per cent), which did not affect outcome, may be attributable to the use of supplemental sedatives. The incidence of upper airway abstruction $(7.8$ per cent) was similar to that of previous studies. Vascular compromise resulted from the procedure in 33 patients, necessitating surgical correction in 16. Cardiac perforation occurred in four cases, causing one death. Pulmonary valve stenosis was most amenable to balloon dilatation and aortic valve stenosis least amenable. Ketamine was the anaesthetic agent preferred by cardiologists for use in the catheterisation suite when general anaesthesia was required. Vigilant monitoring by anaesthetic staff is necessary during the procedure, and avoidance of concomitant narcotics is recommended if a ketamine technique with spontaneous ventilation is used.
\end{abstract}

\section{Key words}

ANAESTHESIA: paediatric; ANAESTHETIC TECHNIQUES: inhalation, intravenous narcotic, sedation; ANAESTHETICS, INTRA VENOUS: ketamine; HEART: catheterisation, balloon dilatation/occlusion, aortic valve, aortic coarctation, patent ductus arteriosus, pulmonary valve stenosis, pulmonary artery stenosis.

From the Department of Anaesthesia, the Division of Cardiology (Department of Paediatrics) and the Research Institute, The Hospital for Sick Children; and the Department of Anaesthesia, University of Toronto, Toronto, Ontario.

Presented in part at the Canadian Anaesthetists' Society annual meeting in Halifax, June 1988.

Address correspondence to: Dr. Frederick A. Burrows, Department of Anaesthesia, The Hospital for Sick Children, 555 University Avenue, Toronto, Ontario, Canada M5G 1X8.
In recent years interventional cardiologic procedures have replaced thoracic and cardiac surgery in the treatment of certain cardiac anomalies in children. Balloon dilatation is particularly effective in treating pulmonary valve stenosis and is also performed as a nonsurgical alternative for patients with aortic valve stenosis, recoarctation of the aorta and pulmonary artery stenosis. Insertion of an occlusion device is used to treat patent ductus arteriosus.

Procedures performed in the cardiac catheterisation suite require a darkened room, allow poor access to the often critically ill patient and present the potential for sudden devastating complications, including rupture of a cardiac chamber. In addition, interventional procedures require a steady haemodynamic state before oxygen saturation and pressures in the various cardjac chambers are determined, because management decisions are based on estimates of intracardiac shunts, vascular resistances and pulmonary:systemic flow ratios. During balloon dilatation the patient must remain motionless.

Cardiologists and anaesthetists have used a wide variety of agents to sedate and/or anaesthetise children for these procedures but no technique has achieved universal acceptance. We review our anaesthetic experience with interventional cardiologic procedures at The Hospital for Sick Children, Toronto.

\section{Methods}

With approval from the Committee on Human Research we reviewed the charts of all patients who had undergone interventional cardiologic procedures from January 1984 to July 1987. Anaesthetic/sedation techniques were noted. Complications related to anaesthesia/sedation or the procedure were reviewed. Patients were subsequently divided into four groups depending on the technique used: intravenous or intramuscular sedation administered under the supervision of the cardiologist, ketamine given by infusion, inhalational anaesthesia with controlled ventilation, and narcotic anaesthesia. Techniques in the latter three groups were administered by a staff anaesthetist.

Statistical analysis was performed using $\chi^{2}$ analysis 
TABLE I Interventional cardiologic procedures and anaesthetic techniques

\begin{tabular}{llllll}
\hline Procedure & Sedation & Ketamine & Inhalation & Narcotic & Total no. of patients \\
\hline Pulmonary valve dilatation & 14 & 34 & 17 & 5 & 70 \\
Aortic valve dilatation & 5 & 7 & 10 & 17 & 39 \\
Dilatation of recoarctation of the aorta & 6 & 12 & 6 & 2 & 26 \\
Pulmonary artery dilatation & 0 & 15 & 3 & 1 & 19 \\
Occlusion of patent ductus arteriosus & 1 & 22 & 6 & 1 & 30 \\
\hline Total & 26 & 90 & 42 & 26 & 184 \\
\hline
\end{tabular}

with the Bonferroni correction for multiple comparisons. A $P<0.05$ was considered significant.

\section{Results}

Patients and procedures

One hundred and eighty-four dilatation/occlusion procedures lasting 1.4 to 6.0 hours were carried out in 176 children (Table I). The patients (104 males, 72 females) ranged in age from 12 hours to 16.7 years old and in weight from 2.6 to $78.4 \mathrm{~kg}$. Seventy-three patients arrived in the catheterisation suite without and 111 with premedication: the most common premedications were oral diazepam (38 procedures) and intramuscular $\mathrm{CM}_{3}(1 \mathrm{ml}$ contains meperidine $25 \mathrm{mg}$, chlorpromazine $6.25 \mathrm{mg}$ and promethazine $6.25 \mathrm{mg}$ ) (24 procedures).

\section{Monitoring}

The electrocardiogram of all patients was monitored. Oxygen saturation was monitored continuously by pulse oximetry. Arterial blood pressure was monitored by sphygmomanometry and a doppler flow probe. When indicated by patient status, arterial pressure was monitored directly by establishing arterial catheterisation. However, when an arterial catheter was needed for the catheterisation procedure it was also used to monitor arterial pressure and to obtain arterial blood samples. Rectal temperature was monitored in all anaesthetised patients. The use of a precordial stethoscope was not possible due to interference with fluoroscopy. For intubated patients ventilation was monitored by use of an end-tidal $\mathrm{CO}_{2}$ monitor. Depending upon the nature of the underlying lesion, end-tidal $\mathrm{CO}_{2}$ measurements underestimated the true arterial $\mathrm{PCO}_{2}$ in patients with congenital heart disease and therefore adequacy of ventilation may require confirmation by blood gas analysis. ${ }^{1-3}$ In sedated patients and unintubated patients breathing spontaneously, ventilation was monitored by the use of an end-tidal $\mathrm{CO}_{2}$ monitor with the sampling site inserted into the mask supply of air or an air/oxygen mixture. This technique proved to be quite satisfactory for monitoring ventilation but again underestimated the arterial $\mathrm{PCO}_{2}$.

\section{Sedation and anaesthetic techniques}

Twenty-six of the 184 procedures (14 per cent) were carried out using sedation under the supervision of the cardiologist with no anaesthetist in attendance (Table I). In 18 of these 26 patients $\mathrm{CM}_{3} 0.05-0.1 \mathrm{ml} \cdot \mathrm{kg}^{-1}$ had been given IV or IM 30 to 60 minutes before the procedure. (Six other patients premedicated with $\mathrm{CM}_{3}$ were subsequently anaesthetised.) Further sedation administered at the discretion of the attending cardiologist included diazepam (11), meperidine (2) and additional $\mathrm{CM}_{3}$ (2). The remaining eight patients in this group were neonates whose tracheas were intubated before arrival in the catheterisation suite.

Ketamine was the agent selected most frequently ( $P<$ 0.05 ) when an anaesthetist participated in the case ( 90 of 158 cases). In all 90 patients, an anticholinergic agent was administered IV or IM before induction with ketamine. Anaesthesia was maintained with ketamine infusion. In 12 patients, anaesthesia was maintained with ketamine alone while 54 were given supplemental diazepam, 12 diazepam and fentanyl and 12 lorazepam and/or droperidol. The mean dose of ketamine was $6.1 \mathrm{mg} \cdot \mathrm{kg}^{-1} \cdot \mathrm{hr}^{-1}$ (range $1-13 \mathrm{mg} \cdot \mathrm{kg}^{-1} \cdot \mathrm{hr}^{-1}$ ). Three patients were intubated with pancuronium after induction with ketamine. Anaesthesia was maintained with a ketamine infusion, pancuronium and controlled ventilation. Of the remaining 87 patients, 82 breathed spontaneously throughout the procedure while five developed severe upper airway obstruction necessitating intubation and controlled ventilation.

Forty-two patients received an inhalational anaesthetic. Anaesthesia was induced IV in 39 (thiopentone in 29, ketamine in five and fentanyl in five) and by inhalational agents in three patients. All patients in this group received a neuromuscular relaxant and their tracheas were intubated and their lungs ventilated. Anaesthesia was maintained with only an inhalational agent in 18 patients and with a narcotic supplement in 24 . Twenty-eight patients received halothane, 13 isoflurane and one a mixture of oxygen and nitrous oxide without a narcotic.

A primarily narcotic-based technique was used in 26 patients. Twenty-one patients received fentanyl (1.5- 
$36 \mu \mathrm{g} \cdot \mathrm{kg}^{-1}$, mean $\left.=8.6 \mu \mathrm{g} \cdot \mathrm{kg}^{-1}\right)$ and four meperidine $\left(0.1-1.5 \mathrm{mg} \cdot \mathrm{kg}^{-1}\right.$, mean $\left.=0.9 \mathrm{mg} \cdot \mathrm{kg}^{-1}\right)$; in one, a preoperative morphine infusion was continued at $20 \mu \mathrm{g}$. $\mathrm{kg}^{-1} \cdot \mathrm{hr}^{-1}$. A narcotic-relaxant technique with controlled ventilation was used in 16 patients. In the remaining ten patients the narcotic was titrated to obtain the desired effect with the patient breathing spontaneously.

\section{Complications}

A total of 118 complications were identified (incidence of 64.1 per cent). Thirty-five ( 29.7 per cent) were related to the anaesthesia and 83 (70.3 per cent) to the procedure itself.

Respiratory complications occurred in 28 procedures and were most common $(\mathrm{P}<0.05)$ in the group anaesthetised with ketamine (Table II). Hypercarbia (range $48-68 \mathrm{mmHg}$, mean $=55 \mathrm{mmHg}$ ) developed in 21 patients and upper airway obstruction/laryngospasm in seven, necessitating intubation in five. All patients with airway problems and 14 of the 21 with hypercarbia had been anaesthetised with ketamine. Twelve of these had received both a benzodiazepine and a narcotic as premedication and/or in incremental doses during the procedure.

Other anaesthesia-related complications included delayed recovery after ketamine in one case and difficulty in reversing neuromuscular blockade after metocurine in another. One patient had hallucinations on emergence from ketamine. In one child, improper positioning resulted in ulnar nerve injury with tingling and numboess in the left thumb and index finger and associated muscle weakness. This resolved spontaneously before discharge. One patient susceptible to malignant hyperthermia became febrile after a trigger-free anaesthetic. Subsequent creatine phosphokinase results were normal and an allergic reaction to the angiographic dye was implicated as the cause of the fever. ${ }^{4,5}$

Vascular thrombosis or injury to the catheterised vessel was the most common complication (33): seven thromboses/injuries resolved with heparin therapy, ten necessitated fibrinolytic therapy and 16 were repaired surgically. The vascular compromise was completely reversed in all patients except one who now has impaired lower extremity growth on the affected side.

Cardiovascular instability was seen in 28 procedures. It

TABLE II Respiratory complications

\begin{tabular}{llcll}
\hline & $\begin{array}{l}\text { Sedation } \\
N=26\end{array}$ & $\begin{array}{l}\text { Ketamine } \\
N=90\end{array}$ & $\begin{array}{l}\text { Inhalation } \\
N=42\end{array}$ & $\begin{array}{l}\text { Narcotic } \\
N=26\end{array}$ \\
\hline Obstruction & 0 & 7 & 0 & 0 \\
Hypercartia & 1 & 14 & 2 & 4 \\
\hline Total & 1 & 21 & 2 & 4 \\
\hline
\end{tabular}

was transient in 19 , related to catheter manipulation and catheter-induced arrhythmias in 18 and to myocardial depression due to halothane in one. In four cases it resulted from acute aortic insufficiency after aortic valve dilatation: three of these patients required urgent valve replacement, leading to intraoperative death in one. A neonate with critical aortic stenosis receiving prostaglandin and dopamine infusions before the procedure could not be resuscitated after catheter-induced ventricular fibrillation. Cardiac perforation occurred in four patients, two of which required urgent thoracotomy: resuscitation was successful in a patient with right ventricle perforation, but a child with an aortic tear died despite thoracotomy and drainage of the haemopericardium.

Embolisation of a patent ductus arteriosus occlusion device occurred in two patients. In one, the device embolised to the bifurcation of the iliac artery and surgical retrieval involved aortic cross clamping. The other patient had to be placed on cardiopulmonary bypass to retrieve the device from the right ventricle.

One 11-month-old infant sustained a massive left cerebral hemisphere infarct during attempted dilatation of a recoarctation of the aorta and was subsequently declared brain dead. A left carotid doppler flow probe is now used in all patients undergoing dilatation of recoarctation of the aorta in an attempt to prevent recurrence of this complication.

Other complications from the procedure itself included subacute bacterial endocarditis (two), infection at the catheterisation site (one) and haemorrhage from the catheterisation site (six). One patient developed a rash, presumed to be caused by the dye.

\section{Outcome}

Pulmonary valve stenosis was the most amenable to balloon dilatation (Figure), while aortic valve stenosis was the least amenable and was associated with three of the four deaths.

\section{Discussion}

Since $1958 \mathrm{CM}_{3}$ has been widely used by cardiologists for sedation before cardiac catheterisation. However, Goldberg and associates demonstrated a marked increase in pulmonary vascular resistance, a decrease in systemic resistance and tachycardia with its use in dogs. ${ }^{6}$ These changes may affect the magnitude of left-to-right shunts and prevent accurate assessment of the patient's normal haemodynamic state. Other investigators have reported significant respiratory depression, hypotension, extrapyramidal effects and prolonged sedation. ${ }^{7.8}$ Furthermore, sedation with $\mathrm{CM}_{3}$ does not always ensure that the patient remains motionless during inflation of the balloon or placement of the occlusion device. Of our 18 patients 


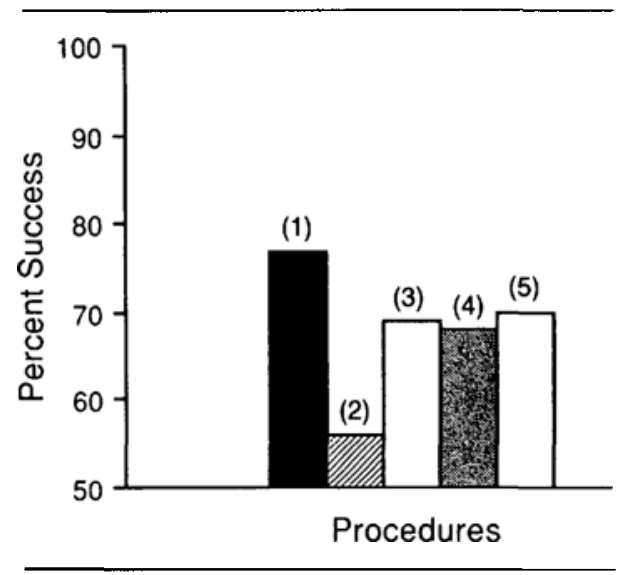

FIGURE Success rates of 184 interventional cardiologic procedures: pulmonary value dilatation (1); aortic valve dilatation (2); dilatation of recoarctation of the aorta (3); pulmonary artery dilatation (4); occlusion of patent ductus arteriosus (5)

sedated with $\mathrm{CM}_{3}$, two developed respiratory depression and two had prolonged sedation necessitating close nursing observation after the procedure. We recommend close monitoring of respiratory status and vital signs after use of $\mathrm{CM}_{3}$.

Ketamine was the anaesthetic agent used most frequently in our procedures $(90 / 184)$. It was preferred by both the anaesthetist and the cardiologist because it produces no significant haemodynamic changes in children during cardiac catheterisation. ${ }^{9,10}$ In addition, it does not significantly affect functional residual capacity (FRC) after induction of anaesthesia. In long procedures with other anaesthetic techniques the FRC may fall below the closing capacity, resulting in gas trapping and increased intrapulmonary shunting that alters blood gas values obtained during the procedure. " However, patients anaesthetised with ketamine may demonstrate nonpurposeful movements with or without noxious stimuli. To minimise these movements, many of our patients received supplemental sedation with benzodiazepines and/or narcotics.

The relatively high incidence of respiratory complications in patients who were given ketamine did not adversely affect the ultimate outcome. Our incidence of upper airway obstruction with ketamine $(7 / 90)$ is similar to that reported by other authors $(8 / 40$ and $3 / 40) v^{12,13}$ The incidence of hypercarbia in our patients was higher than reported elsewhere ${ }^{9.13}$ and may be attributable to the supplemental sedation. ${ }^{14}$ Morray et al. observed no increase of $\mathrm{PCO}_{2}$ in 20 patients anaesthetised with rectal thiamylal and ketamine, ${ }^{9}$ while other studies reported a mild increase $(5 \mathrm{mmHg})$ in spontaneously breathing patients who received ketamine as the sole anaesthetic and a further increase after the administration of supplemental narcotics. ${ }^{13.14}$ In our opinion, ketamine remains an excellent choice in the catheterisation suite but vigilant monitoring by anaesthetic personnel and avoidance of concomitant narcotics are recommended.

Tracheal intubation and controlled ventilation during cardiac catheterisation have been discouraged because of possible interference with differential intravascular and intracardiac pressure recordings. Manners and Codman reported increased intracardiac shunts and decreased pulmonary:systemic flow ratios and cardiac output with the institution of controlled ventilation. ${ }^{15}$ However, these differences were not sufficient to alter decisions about the subsequent management of any of their patients. In high-risk patients in whom a secure airway and controlled ventilation are considered essential, low concentrations of inhalational anaesthetics may be used without significantly affecting clinical decisions that are based on cardiovascular measurements.

There is no "ideal" anaesthetic technique that can be universally applied in patients undergoing interventional cardiologic procedures. The technique should be modified depending on the cardiac anomaly, the patient's clinical condition and the requirements of the cardiologist. Our experience indicates that these procedures are associated with complications requiring the immediate availability of an operating room and cardiopulmonary bypass, irrespective of the anaesthetic technique selected. Sophisticated monitoring is needed, along with a high index of suspicion, which may permit early recognition of complications and avert disastrous results.

\section{Acknowledgement}

This paper was prepared with the assistance of the Medical Publications Department, The Hospital for Sick Children, Toronto.

\section{References}

1 Lindahl SGE, Yates AP, Hatch DJ. Relationship between invasive and noninvasive measurements of gas exchange in anesthetized infants and children. Anesthesiology 1987; 66: 168-75.

2 Fletcher $\boldsymbol{R}$. Invasive and noninvasive measurement of the respiratory deadspace in anesthetized children with cardiac disease. Anesth Analg 1988; 67: 442-7.

3 Burrows FA. Physiological deadspace, venous admixture, and the arterial to end-tidal carbon dioxide difference in infants and children undergoing cardiac surgery. Anesthesiology 1989; 70: 219-25. 
4 Lalli $A F$. Contrast media reactions. Data analysis and hypothesis. Radiology 1980; 134:1-12.

5 Goldberg $M$. Systemic reactions to intravascular contrast media. A guide for the anesthesiologist. Anesthesiology 1984; 60: 46-56.

6 Goldberg SJ, Linde LM, Wolfe RR, Griswold W, Momma $K$. The effects of meperidine, promethazine, and chlorpromazine on pulmonary and systemic circulation. Am Heart J 1969; 77: 214-21.

7 Nahata MC, Clotz MA, Krogg EA. Adverse effects of meperidine, promethazine, and chlorpromazine for sedation in pediatric patients. Clin Pediatr 1985; 24: $558-60$.

8 Cohen GH, Casta A, Sapire DW, Talabi A. Decorticate posture following "cardiac cocktail": a transient complication of sedation for catheterization. Pediatr Cardiol 1982; 2: 251-3.

9 Morray JP, Lynn AM, Stamm SJ, Herndon PS, Kawabari I, Sievenson JG. Hemodynamic effects of ketamine in children with congenital heart disease. Anesth Analg 1984; 63: 895-8.

10 Hickey PR, Hansen DD, Cramolini GM, Vincent $R N$, Lang $P$. Pulmonary and systemic hemodynamic responses to ketamine in infants with normal and elevated pulmonary vascular resistance. Anesthesiology 1985; 62: 287-93.

11 Shulman D, Beardsmore CS, Aronson HB, Godfrey $S$. The effect of ketamine on the functional residual capacity in young children. Anesthesiology 1985; 62: 551-6.

12 Faithfull NS, Haider $R$. Ketamine for cardiac catheterisation: an evaluation of its use in children. Anaesthesia 1971; 26: 318-23.

13 Coppel DL, Dundee JW. Ketamine anaesthesia for cardiac catheterisation. Anaesthesia 1972; 27: 25-31.

14 Bourke DL, Malit LA, Smith TC. Respiratory interactions of ketamine and morphine. Anesthesiology 1987; 66: 153-6.

15 Manners $J M$, Codman VA. General anaesthesia for cardiac catheterisation in children. Araesthesia 1969; 24:

$541-53$.
Résumé

Les techniques anesthésiques et de sédation ainsi que les complications et les issues ont été revues chez 176 enfants subissant 184 procédures cardiaques. Les techniques ont inclu soit la sédation seulement, soit l'anesthésie d la kétamine, aux agents d'inhalation ou aux narcotiques. La perfusion de kétamine était la technique la plus fréquemment utilisée. La kétamine était associce d̀ une plus grande incidence de complication respiratoire $(\boldsymbol{P}<0.05)$ comparativement aux autres techniques. La plus grande incidence d'hypercarbie (15.6 pour cent), n'ayant pas affecté l'issue, pourrait être attribuée d' l'utilisation additionnelle de sédarifs. L'incidence d'obstruction des voies aériennes supérieures ( 7.8 pour cent) était similaire aux études préalables. Un problème vasculaire suite da la procédure fut observé chez 33 patients dont 16 ont requis une correction chirurgicale. Une perforation cardiague est survenue dans quatre cas provoquant le décès d"un seul patient. La sténose de la valve pulmonaire érait la procédure la plus susceptible d'être dilatée et la sténose de la valve cortique la moins susceptible. La kétamine étail l'agent anesthésique préféré par les cardiologistes lors des cathétérisations quand une anesthésie générale était requise. Une surveillance vigilante par une équipe anesthésique fut nécessaire durant la procédure. Il faut aussi éviter l'administration de narcotiques si la kétamine est administrée en respiration spontanée. 